\title{
PENERAPAN BAHAN AJAR TRIGONOMETRI DENGAN MODEL MATEMATIKA KNISLEY UNTUK MENINGKATKAN KEMAMPUAN BERPIKIR KRITIS MATEMATIK
}

\author{
Puji Nurfauziah $^{1}$, Veny Triyana Andika Sari ${ }^{2}$ \\ ${ }^{1,2}$ Pendidikan Matematika, IKIP Siliwangi \\ E-mail: $\quad$ zielazuardi@gmail.com ${ }^{1)}$ \\ venytriyana050113@gmail.com ${ }^{2)}$
}

Received 26 September 2018; Received in revised form 8 November 2018; Accepted 21 December 2018

\begin{abstract}
The aim of this study is to determine the improvement of students' critical thinking skills in trigonometry courses whose learning uses trigonometric teaching materials with knisley mathematical models compared to those that do not use teaching materials. The method used in this study is quasi-experimental used pretest posttest nonequivalent control group design with a sample 53 students in experiment class and 51 students in control class. The instrument used in this study is a test of critical thinking skills as much as 5. Instrument data is used to obtain n-gain data which is than analyzed using statistical tests with the stages of normality test, homogeneity test and t' test. Based on the results of the data statistic, it can be concluded that the improvement of students' critical thinking skills in learning using trigonometric teaching materials with knisley mathematical models is better than those who do not use teaching materials.
\end{abstract}

Keywords: critical thinking ability; knisley mathematical model; trigonometric teaching materials.

\section{PENDAHULUAN}

Trigonometri merupakan salah satu pokok bahasan yang dipelajari di dalam mata pelajaran matematika. Selain hal tersebut, trigonometri juga menjadi salah satu pokok bahasan yang berada pada ujian nasional sesuai dengan peraturan menteri no 75 tahun 2009 (Permendiknas, 2010) bahwa standar kompetensi lulusan pada pokok bahasan trigonometri yaitu Memahami konsep perbandingan, fungsi, persamaan, dan identitas trigonometri, melakukan manipulasi aljabar untuk menyusun bukti serta mampu menggunakannya dalam pemecahan masalah.

Selain hal tersebut, trigonometri juga merupakan konsep yang sukar untuk difahami sehingga tidak maksimalnya menguasai konsep trigonometri (Wulandari, Mardiyana, \& Kusmayadi, 2015; Trisnawati, Pratiwi, Nurfauziah, \& Maya, 2018; Lado et al.,
2016; Listiyana, 2012; Jingga, Mardiyana, \& Setiawan, 2010; Abidin, 2012). Berdasarkan hasil observasi lapangan, banyak ditemukan mahasiswa yang mengalami kesulitan di dalam memahami konsep trigonometri dengan alasan karena terlalu banyaknya rumus trigonometri sehingga mahasiswa sulit menghafal atau mendefinisikan. Berangkat dari hal tersebut, tugas guru matematika yaitu harus dapat menguasai dan menyampaikan konsep trigonometri dengan baik agar sesuai dengan tujuan pembelajaran. Penguasaan konsep tersebut dimulai dari kegiatan perkuliahan, dimana di dalam kegiatan perkuliahan pada program studi pendidikan matematika, mahasiswa dituntut untuk mengikuti perkuliahan trigonometri. Mahasiswa diarahkan agar dapat mengembangkan kemampuan berpikir kritisnya di dalam kegiatan perkuliahan trigonometri. 
Berdasarkan beberapa penelitian (Ikhsan, Munzir, \& Fitria, 2017) Dengan memiliki kemampuan berpikir kritis yang baik, mahasiswa dapat mengembangkan konsep trigonometri dengan baik pula dan tidak akan terfokus pada satu konsep atau pengetahuan yang telah dimilikinya. Karakter berpikir kritis identik dengan kesadaran akan kemampuan dirinya dalam mengembangkan berbagai cara yang ditempuh untuk menyelesaikan suatu pemasalahan (Ikhsan, dkk., 2017).

Selain itu berpikir kritis juga dikatakan sebagai berpikir reflektif yang beralasan dan difokuskan pada penetapan apa yang diyakini atau dilakukan, Baron \& Steinberg (Hendriana \& Soemarmo, 2014). Berpikir kritis meliputi memahami dan merumuskan masalah, mengumpulkan dan menganalisis informasi yang diperlukan dan dapat dipercaya, merumuskan praduga dan hipotesis, menguji hipotesis secara logis, mengambil kesimpulan secara hati-hati, melakukan evaluasi dan memutuskan sesuatu yang akan diyakini atau sesuatu yang akan dilakukan, serta meramalkan konsekuensi yang mungkin terjadi (Abdullah, 2013).

Berpikir kritis merupakan kemampuan yang sangat penting di dalam dunia sosial saat ini, Inch (Inch, 1989) mengemukakan "critical thinking a vital skills in today's society, enables a person to investigate a situation, problem, question, or phenomenom to arrive at viable hypothesis or conclusion". Dengan kemampuan berpikir kritis yang baik, maka kita dapat menghadapi berbagai situasi yang terjadi di dalam kehidupan sehari-hari. Agar kemampuan berpikir kritis mahasiswa berkembang dan meningkat, maka kegiatan pembelajaran trigonometri di dalam perkuliahan jelas harus lebih bermakna. Salah satu cara yang digunakan yaitu dengan menggunakan bahan ajar atau modul. Modul mempunyai self instruction yang memungkinkan mahasiswa dapat belajar secara mandiri menggunakan modul dan dosen tidak lagi menjadi satu- satunya sumber belajar mahasiswa (Pratiwi, 2014).

Bahan ajar yang digunakan di dalam penelitian ini yaitu bahan ajar trigonometri dengan model Matematika Knisley. Dimana di dalam bahan ajar trigonometri tersebut mencakup indikator-indikator model matematika knisley. Tahapan model Matematika Knisley yaitu Concrete - reflective, Concrete - active, Abstract - reflective, Abstract - active, Knisley (Nurfauziah \& Sari, 2018). Knisley lebih lanjut menjelaskan mengenai gaya belajar kolb dapat diartikan sebagai gaya belajar matematika dengan merepresentasikan tahapan-tahapan tersebut seperti di bawah ini.

Tabel 1. Representasi Gaya Belajar Kolb

\begin{tabular}{cc}
\hline Kolb's Learning & Equivalent \\
Styles & Mathematical Style \\
\hline Concrete, & Allegorizer \\
Reflextive & \\
Concrete, Active & Integrator \\
Abstract, Reflective & Analyzer \\
Abstract, Active & Synthesizer \\
\hline & (Knisley, 2000)
\end{tabular}

(Knisley, 2000)

Berdasarkan Tabel 1, tahapantahapan tersebut dapat direpresentasikan sesuai dengan Haety \& Mulyana (2013) bahwa pada tahap concrete-active siswa sebagai allegorizer dimana siswa mempelejari konsep baru berdasarkan konsep yang dimiliki sebelumnya; concrete-active siswa sebagai integrator dimana siswa mencoba menambahkan konsep baru melalui eksplorasi karakteristik konsep baru tersebut; abstract-Reflective siswa sebagai analyzer dimana siswa menganalisis konsep yang dikenalkan oleh guru dengan memperhatikan representasinya 
dalam tugas konkret- reflektif dan konkret-aktif; abstract-active siswa sebagai synthesizer dimana siswa dapat membuat prosedur di dalam memecahkan masalah.

Berdasarkan beberapa penelitian yang telah dilakukan, bahwa model matematika knisley dapat memudahkan mengidentifikasi pemahaman mahasiswa ketika sedang pembelajaran serta layak menjadi acuan pengembangan bahan ajar (Dedy, Mulyana, \& Sudihartinih, 2012; Septiyana et al., 2016). Oleh karena itu, penelitian ini bertujuan untuk mengetahui peningkatan kemampuan berpikir kritis matematik mahasiswa yang pembelajarannya menggunakan bahan ajar trigonometri dengan model matematika knisley.

\section{METODE PENELITIAN}

Metode yang digunakan di dalam penelitian ini yaitu quasi eksperimen dengan desain pretest postest nonequivalen control group design. Pada desain ini terdapat dua kelas, dimana kelas eksperimen mendapatkan pembelajaran trigonometri dengan menggunakan bahan ajar trigonometri dengan model matematika knisley, sedangkan kelas kontrol menggunakan pembelajaran biasa tanpa bahan ajar trigonometri dengan model matematika knisley. Populasi dari penelitian ini adalah seluruh mahasiswa semester empat pada program studi pendidikan matematika, dan sampelnya terdiri dari 53 mahasiswa di kelas eksperimen dan 51 mahasiswa di kelas kontrol. Instrumen yang digunakan di dalam penelitian ini berupa lima soal kemampuan berpikir kritis dengan meliputi indikator mempertanyakan isue, merepresentasikan tujuan akhir, mengumpulkan data, mendefinisikan konsep dengan teori-teori, membuat dugaan, menganalisis dari berbagai macam sudut pandang, menginterpretasikan berbagai sudut pandang yang berbeda, implikasi dan konsekuensi pemikiran (Inch, 1989).

Materi trigonometri yang terdapat di dalam instrumen meliputi: perbandingan segitiga siku-siku dan perhitungan pada segitiga siku-siku, konsep perbandingan trigonometri untuk sudut-sudut berelasi dan grafik fungsi trigonometri, konsep identitas trigonometri, persamaan dan pertidaksamaan trigonometri, konsep aturan sinus dan aturan kosinus dan konsep luas segitiga, rumus jumlah, selisih, sudut ganda, sudut tengahan, perkalian dan penjumlahan, aplikasi trigonometri dalam menyelesaikan soal.

Hasil dari pretes dan postes kemampuan berpikir kritis matematik kemudian dicari $\mathrm{N}$-gain dan dianalisis dengan menggunakan software SPSS 16 untuk menguji hipotesis penelitian yaitu: peningkatan kemampuan berpikir kritis matematik mahasiswa yang menggunakan bahan ajar trigonometri lebih baik daripada yang tidak menggunakan bahan ajar trigonometri.

\section{HASIL PENELITIAN DAN PEMBAHASAN}

Hipotesis dalam penelitian ini yaitu: peningkatan kemampuan berpikir kritis matematik mahasiswa yang menggunakan bahan ajar trigonometri lebih baik daripada yang tidak menggunakan bahan ajar trigonometri. Data yang didapatkan di dalam penelitian yaitu data pretes, postes dan $\mathrm{N}$-gain. Kemudian nilai $\mathrm{N}$-gain diuji statistik dengan menggunakan SPSS 16. Tabel 2. Deskriptif Statistik

\begin{tabular}{lrrrrrr}
\hline & & & & & \multicolumn{2}{c}{$\begin{array}{c}\text { Std. } \\
\end{array}$} \\
& $N$ & Min & Max & Mean & Deviation \\
\hline N-gain Eks & 53 &,- 25 &, 88 &, 5362 &, 22379 \\
N-gain Kon & 51 &, 00 &, 74 &, 3841 &, 14192 \\
\hline
\end{tabular}


Pada Tabel 2, dapat terlihat bahwa kelas eksperimen memiliki nilai rata-rata lebih besar daripada kelas kontrol. Hal tersebut secara deskriptif mengindikasikan bahwa kelas eksperimen lebih baik daripada kelas kontrol. Akan tetapi untuk menguji kebenarannya diperlukan uji statistik. Berikut hasil uji statistik yang telah dilakukan.

Tabel 3. Uji Normalitas

\begin{tabular}{|c|c|c|c|}
\hline & \multicolumn{3}{|c|}{ Kolmogorov-Smirnov ${ }^{\mathrm{a}}$} \\
\hline & Statistic & $\mathrm{df}$ & Sig. \\
\hline $\mathrm{N}$-gain Eks & , 105 & 51 & 200 \\
\hline $\mathrm{N}$-gain Kon & , 100 & 51 & ,200 \\
\hline
\end{tabular}
normalitas $\mathrm{N}$-gain kemampuan berpikir kritis matematik mahasiswa yang pembelajarannya menggunakan bahan ajar trigonometri dengan model matematika knisley didapatkan hasil bahwa nilai sig. kelas eksperimen dan kelas kontrol > 0,05 yang berarti bahwa data $\mathrm{N}$-gain kelas eksperimen dan kelas kontrol berdistribusi normal. Karena data tersebut berdistribusi normal, maka analisis data selanjutnya yaitu uji homogenitas.

Tabel 4. Uji Homogenitas

\begin{tabular}{rrrr}
\hline Levene Statistic & df1 & df2 & Sig. \\
\hline 5,346 & 1 & 102 &, 023
\end{tabular}

Dari Tabel 4, didapatkan nilai sig. $<0,05$ yang berarti bahwa data $\mathrm{N}$ gain tidak homogen. Karena data berdistribusi normal dan tidak homogen, sehingga analisis data dilanjutkan dengan uji t'. berikut hasil uji t' dengan menggunakan SPSS 16.

Tabel 5. Uji t.

\begin{tabular}{llllll}
\hline & & \multicolumn{3}{c}{ t-test for Equality of Means } \\
\cline { 3 - 6 } & & & & \multicolumn{2}{c}{$\begin{array}{c}\text { Sig. (2- } \\
\text { tailed) }\end{array}$} \\
\hline Nilai & $\begin{array}{l}\text { Equal } \\
\text { variances } \\
\text { assumed }\end{array}$ & 4,121 & 102 &, 000 \\
\hline
\end{tabular}

\begin{tabular}{|c|c|c|c|c|}
\hline & & \multicolumn{3}{|c|}{ t-test for Equality of Means } \\
\hline & & $\mathrm{T}$ & df & $\begin{array}{l}\text { Sig. (2- } \\
\text { tailed) }\end{array}$ \\
\hline \multirow[t]{2}{*}{ Nilai } & $\begin{array}{l}\text { Equal } \\
\text { variances } \\
\text { assumed }\end{array}$ & 4,121 & 102 &, 000 \\
\hline & $\begin{array}{l}\text { Equal } \\
\text { variances } \\
\text { not } \\
\text { assumed }\end{array}$ & 4,156 & 88,475 &, 000 \\
\hline
\end{tabular}

Berdasarkan Tabel 5, pada uji t' yaitu pada nilai Equal variances not assumed didapatkan kesimpulan bahwa sig < 0,05. Berdasarkan hasil uji t' tersebut dapat terlihat bahwa kelas eksperimen lebih baik daripada kelas kontrol. Hal tersebut sesuai dengan gambaran dari Tabel 2, pada tabel deskriptif statistik yang menunjukkan bahwa rata-rata n-gain kelas eksperimen lebih besar daripada rata-rata n-gain kelas kontrol, sehingga berdasarkan rata-rata dan uji statistik dapat diinterpretasikan bahwa peningkatan kemampuan berpikir kritis matematik mahasiswa yang menggunakan bahan ajar trigonometri lebih baik daripada yang tidak menggunakan bahan ajar trigonometri.

Kegiatan pembelajaran di dalam kelas dengan menggunakan bahan ajar trigonometri dengan model matematika knisley sangat menekankan pada kemampuan berpikir kritis. Dimana pada tahap-tahap model matematika knisley seperti yang telah diungkapkan sebelumnya, pada tahap concretereflective bahwa mahasiswa sebagai allegorizer dimana mahasiswa mempelejari konsep baru mengenai trigonometri berdasarkan konsep yang dimiliki sebelumnya mengenai trigonometri, dengan salah satu contohnya yaitu mahasiswa sudah mengetahui rumus mengenai sudut berelasi. Tetapi dengan menggunakan bahan ajar trigonometri dengan model matematika knisley, mahasiswa menemukan konsep berdasarkan analisis gambar yang berdasar pada 
pengetahuan sebelumnya mengenai konsep trigonometri.

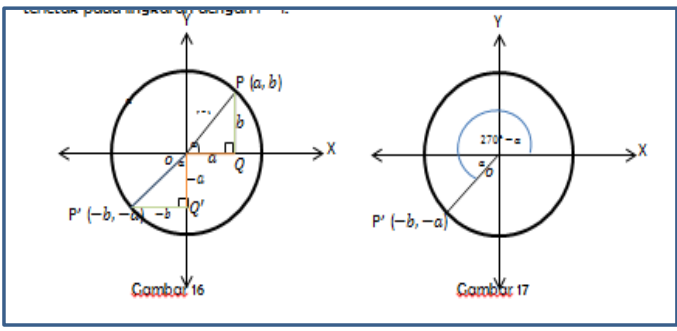

Gambar 1. Concrete-Gareflective

Pada tahap concrete-active mahasiswa sebagai integrator dimana mahasiswa mencoba menambahkan konsep baru dengan melakukan eksplorasi pada penurunan rumus sudut berelasi agar mendapatkan suatu kesimpulan; abstract-Reflective mahasiswa sebagai analyzer dimana mahasiswa menganalisis konsep yang telah diberikan dengan memperhatikan aturan-aturan/sistematika yang terstuktur berdasarkan tahapan sebelumnya mengenai konsep yang telah dipelajari mengenai sudut berelasi; abstract-active mahasiswa sebagai synthesizer dimana mahasiswa dapat membuat prosedur di dalam memecahkan masalah trigonometri sudut berelasi yaitu dengan menyelesaikan permasalahan dengan berbagai cara yang berbeda sesuai dengan apa yang telah di dapat pada tahap-tahap sebelumnya.

Bahan ajar trigonometri dengan model matematika knisley dapat meningkatkan kemampuan berpikir kritis mahasiswa. Karena bahan ajar tersebut meliputi tahapan-tahapan yang dapat mengembangkan kemampuan berpikir kritis mahasiswa. Pembelajaran dengan menggunakan model matematika knisley mendorong mahasiswa aktif dalam belajar, karena terdapat ruang untuk dialog dengan sesama teman maupun dosen diskusi kelompok (sharing) sehingga belajar menjadi lebih efektif (Dedy et al., 2012). Pembelajaran dengan model matematika knisley lebih efektif daripada pembelajaran konvensional ditinjau dari prestasi belajar, kemampuan penalaran (Kusumayanti \& Wutsqa, 2016), selain hal tersebut pembelajaran dengan model matematika knisley juga dapat meningkatkan kemampuan komunikasi (Romadoni, 2016).

\section{KESIMPULAN DAN SARAN}

Berdasarkan hasil analisis data, maka didapatkan kesimpulan bahwa Peningkatan kemampuan berpikir kritis matematik mahasiswa yang menggunakan bahan ajar trigonometri dengan model matematika knisley lebih baik daripada yang tidak menggunakan bahan ajar trigonometri dengan model matematika knisley. Bahan ajar trigonometri dengan model matematika knisley memiliki beberapa kelebihan daripada bahan ajar trigonometri yang ada, karena bahan ajar trigonometri dengan model matematika knisley memiliki tahap-tahap kegiatan pembelajaran dengan diawali pemberian masalah kongkrit (disajikan dalam bentuk gambar dan cerita), langkahlangkah penurunan rumus trigonometri berdasarkan dari masalah kongkrit, alternatif penyelesaian permasalahan trigonometri yang lebih bervariatif.

Terdapat beberapa rekomendasi yang diharapkan dapat dilaksanakan, agar penelitian menjadi lebih sempurna yaitu: 1) diharapkan terdapat penelitian lanjutan mengenai pengembangan bahan ajar yang lebih mendalam mengenai konsep trigonometri menggunakan model matematika knisley; 2) dengan bahan ajar ini diharapkan dapat meningkatkan kemampuan-kemampuan lain selain kemampuan berpikir kritis. 


\section{DAFTAR PUSTAKA}

Abdullah, I. H. (2013). Berpikir Kritis Matematik. Delta-Pi: Jurnal Matematika Dan Pendidikan Matematika ISSN 2089-855X, 2(1), 66-75.

Abidin, Z. (2012). Pendidikan Matematika Fakultas. Jurnal Ilmiah DIDAKTIKA, XIII(1), 183196.

Dedy, E., Mulyana, E., \& Sudihartinih, E. (2012). BERDASARKAN MODEL PEMBELAJARAN MATEMATIKA KNISLEY SEBAGAI UPAYA MENINGKATKAN

KOMPETENSI. PYTHAGORAS, 7(1), 101-112.

Haety, N. I., \& Mulyana, E. (2013). Pengaruh Model Pembelajaran Matematika Knisley Terhadap Peningkatan kemampuan koneksi Matematis Siswa SMA. Jurnal Online Pendidikan Matematika Kontemporer, 1(1), 1-8.

Hendriana, H., \& Soemarmo, U. (2014). Penilaian pembelajaran matematika. Bandung: Refika Aditama.

Ikhsan, M., Munzir, S., \& Fitria, L. (2017). Kemampuan Berpikir Kritis dan Metakognisi Siswa dalam Menyelesaikan masalah Matematika Melalui Pendekatan Problem Solving. Aksioma-Jurnal Pendidikan Matematika FKIP Univ. Muhammadiyah Metro, 6(2), $1-6$.

Inch, E. S. (1989). Critical Thinking and Communication: The Use of Reason in Argument, 6/e. Pearson Education India.

Jingga, A. A., Mardiyana, \& Setiawan,
R. (2010). Purposive Sampling . Jurnal Pendidikan Matematika Dan Matematika (JPMM), 1(5), 48-62.

Knisley, J. (2000). A Four-Stage Model of Mathematical Learning. Journal of the Learning Sciences, (423).

Kusumayanti, A., \& Wutsqa, D. U. (2016). Keefektifan model kolbknisley ditinjau dari prestasi belajar, kemampuan penalaran, dan self-esteem siswa. MaPan: Jurnal Matematika Dan Pembelajaran, 4(1), 29-42.

Lado, H., Hayati, I. N., Akbarita, R., Afifah, A., Evanty, H., Wulan, E. R., ... Arif, S. (2016). Jurnal pembelajaran matematika, (1).

Listiyana, F. (2012). Analisis Kesulitan Siswa Dalam Meyelesaikan Soal Rumus - Rumus Segitiga Pada Materi Trigonometri Kelas X Sman 1 Cawas Kabupaten Klaten. Jurnal Penelitian, 1-18. Retrieved from

http://eprints.ums.ac.id/19448/21/ NASKAH_PUBLIKASI_IDA.pdf

Nurfauziah, P., \& Sari, V. T. A. (2018). Efektivitas Bahan Ajar Trigonometri dengan Model Matematika Knisley. In Prosiding Seminar Nasional Matematika dan Pendidikan Matematika (Vol. 6, p. 305).

Permendiknas. (2010). Ujian Nasional Sekolah Menengah 2009/2010.

Pratiwi, M. (2014). EFEKTIVITAS MODUL ANALISIS KOMPLEKS DENGAN PENDEKATAN KETERAMPILAN PROSES PADA PROGRAM. LEMMA, I(1), 33-42. 
ISSN 2089-8703 (Print) Vol. 7, No. 3 (2018) 356-362

ISSN 2442-5419 (Online)

Romadoni, E. M. C. (2016).

IMPLEMENTASI MODEL

PEMBELAJARAN

MATEMATIKA KNISLEY

MPMK ) DALAM UPAYA

MENINGKATKAN. PROSIDING

Universitas Muhamamadiyah

Surakarta, (Knpmp I), 570-579.

Septiyana, W., Pujiastuti, H., \& Ihsanudin. (2016). Model Pembelajaran Matematika Knisley untuk Meningkatkan Kemampuan Pemahaman Konseptual Matematis Siswa SMP. Jppm, 9(1), 187.

Trisnawati, I., Pratiwi, W., Nurfauziah, P., \& Maya, R. (2018). Analisis kemampuan berpikir kreatif matematis siswa sma kelas xi pada materi trigonometri ditinjau dari self confidence, 1(3), 383-394. https://doi.org/10.22460/jpmi.v1i3. 383-394

Wulandari, I., Mardiyana, \& Kusmayadi, T. A. (2015). DENGAN MENGINTEGRASIKAN PENALARAN. Jurnal Elektronik Pembelajaran Matematika, 3(4), 359-369. 